\title{
ATTITUDES TO WORK
}

\begin{abstract}
A TEAM from the Medical Research Council has carried out an investigation in three large massproduction factories in England to determine the attitudes of the workers to two important aspects of their working life: the operation which they performed at the bench or the conveyor belt, and the system by which they were paid. Its report describes the methods of investigation and the main findings*.

The method used was the direct one of personal interview, each man being invited to answer the interviewer's questions as fully and frankly as he could, and to indicate the strength of his views on each topic by reference to a five-point scale.

The general attitude to the five forms of group payment studied was predominantly favourable, though some forms were more satisfying than others. On the whole, communal bonus and group piecework systems were the most satisfying and group unit and indirect bonus systems the least.

The form of payment was by no means the only determinant of attitude. Other influential factors were: $(a)$ the size and composition of the working group; (b) the type of work; (c) comparisons with other systems of payment; $(d)$ the way a system was administered by the firm; it was impossible to say that one form of payment was intrinsically better or worse than another.

Some of the skilled men in the higher wage groups thought they were underpaid in relation to unskilled workers, and some of the men in the lower wage groups thought that wages were good for the type of work they did. There was, however, a direct relation between attitude to the payment system and actual earnings when the same form of payment yielded different levels of earnings in comparable groups.

Satisfaction with group payment was more marked among men in the higher than in the lower age groups. The older men, as compared with the younger, appreciated the comfort, co-operation and friendly feeling associated with group payment.
\end{abstract}

The attitude to group payment was more favourable in small than in large groups. Men in small groups (less than ten) as compared with men in large groups (more than fifty) spoke more frequently of the favourable effects of group payment on earnings and personal relations, and less frequently of its levelling and restrictive effects. They also had much less to say about slackers.

The reasons for liking and disliking the five forms of group payment were many and varied. According to the classification used in this survey, the largest group of distinguishable comments centred around the effects of group payment on earnings, and this was followed by comments on social aspects and incentive values. There were also many comparisons with other systems of payment.

Comments on the effects of group payment on earnings included references to standard times, rates of payment, the amount and consistency of the weekly wage or bonus, and the levelling effects on earnings. Comments were favourable when standard * Medical Research Council. Special Report Series, No. 292 : A
Study of Attitudes to Factory Work. By S. Wyatt and R. Marriott, assisted by R. A. Denerley, H. Campbell, J. Walker, Yvonne Kapp,
and F. G. L. Stock. Pp. viitil5. (London: H.M. Stationery Office, 1956.) ios. net. times and rates of payment yielded a good and consistent wage or bonus ; they were unfavourable when earnings were adversely affected by anomalies in rates and standards and by material and mechanical difficulties. The results as a whole suggest that good wages, like good rates and standards, tended to be taken for granted, but any downward deviation from the accepted level was usually resented and sometimes strongly condemned.

Some men liked group payment because they all received the same wage, and some disliked it for the same reason. It was also liked by men in the larger groups because it smoothed out the effects of good and bad jobs.

The number of comments on the social aspects of group payment varied with the form of payment; in some they equalled or closely approached the number of comments on monetary aspects and in others they were almost negligible.

Most of the favourable comments referred to the satisfaction derived from working together as a team, and most of the unfavourable comments to slackers. There was some evidence that adverse comments on slackers and slow workers were relatively more numerous when groups were large and the wage incentive was strong; they tended to be less frequent when the rate of working was controlled by the speed of a moving belt. A fairly large proportion of men liked a group payment system because it encouraged them to work. The proportion was highest when groups were small, compact and homogeneous and when the bonus rate increased as the level of efficiency increased. Conversely, a number of men said that group payment was discouraging, because earnings were not related to individual effort and output; this attitude was particularly noticeable in the group of men on indirect bonus. There was also some evidence that the stronger the wage incentive the greater was the resentment towards anything that obstructed it.

The proportion of men who said they were unable to check their earnings ranged from $41 \cdot 7$ per cent to $81 \cdot 2$ per cent in the five factory groups, but the number who gave this as a reason for disliking the payment system was comparatively small. Inability to calculate earnings increased with the complexity of the system, the size of the working group and, presumably, with the inadequacy of the information and explanation given to the workers.

About 40 per cent of the men compared their own system of payment with other systems. Most of the comparisons were with individual piece-rates and there were almost as many favourable as unfavourable comparisons. The attitude to one form of payment (communal bonus) was also influenced by comparisons with an earlier system (group unit).

The opinions of the workers were, on the whole, endorsed by the supervisors, though the latter tended to comment more frequently on the social and administrative aspects of group payment and less frequently on its relation to earnings.

Almost all the supervisors said that the main and often the only incentive to work was the weekly wage, and many of them thought that the workers would be more satisfied with an individual form of payment by results. 
Despite the tentative nature of most of the findings, it is fairly safe to say that group incentive payment schemes are likely to yield the best results when: $(a)$ groups are small, compact and stable; $(b)$ the members of a group are well matched and engaged on the same type of work; $(c)$ the form of payment is simple and the workers are able to translate output into earnings as work proceeds throughout the week ; (d) there are no anomalies in rates and standards within a group or between groups; (e) output depends on the worker rather than on the machine; (f) the operational cycle is fairly short and repetitive; $(g)$ variations in the quality and flow of material are reduced to a minimum ; $(h)$ the group is able to earn a reasonable bonus. (It is generally recognized that the bonus should be about one-third of the time rate, but the optimum rate has never been deternined); (i) there is an atmosphere of mutual trust and understanding between management and workers.

When the operations in a department are too varied and irregular for sectional payment the incentive scheme may have to be related to departmental output. This is fairly straightforward when the product is uniform, but it is not easy when there are several products and the proportions vary from week to week. Under such conditions it is necessary to determine the number of man-hours per unit of output for each type of product and convert them to a common basis. 'The same procedure can, of course, be applied to factory output, though the scheme will lose some of its incentive value as its remoteness from individual effort increases. On the other hand, a payment scheme based on the total output of a department or factory is less costly in administrative and clerical work than one based on the output of individuals or small groups. It also reduces or eliminates many sources of friction and facilitates the movement or interchange of workers.

\section{SCIENCE AND THE LONDON COUNTY COUNCIL}

${ }^{E} \mathrm{EW}$ London citizens are aware of the considerable amount of work done on their behalf by the Scientific Branch of the Public Health Department of the London County Council. Yet this branch, under the scientific adviser, Dr. S. G. Burgess, has a staff of fifty-nine which includes twenty-six graduates. The function of the branch is to advise all departments of the Council on scientific matters. The work of the branch is carried out in three groups of laboratories, the headquarters laboratories at the County Hall and those at the Northern and Southern Outfall Works situated at Beckton and Crossness. A recent report* of the scientific adviser describes the work carried out in 1955. During the year, 30,335 samples were taken in connexion with renewed investigations into sewage treatments, paints and surface coatings, building materials, school meals, drinking water, swimming baths, ventilation of vehicular tunnels, lubricating oils, polishes, disinfectants, insecticides and fungicides and other topics.

New work was commenced on air pollution, regular observations being taken at twenty sites. The

* Lonđon County Council: Public Health Department, Scientiflc Branch. Annual Report of the Scientiftc Adviser for the year 1955.
Pp. 28. (London: London County Council, 1956.) 1s. observations made showed a marked difference between rural and urban conditions, and also variation in different localities within the County due to local sources of pollution. Seasonal fluctuations were clearly marked at all sites, the generally higher level of pollution in winter being due to the combined effect of increased coal consumption and the occurrence of meteorological conditions unfavourable to the dispersion of chimney gases. When the results are examined over a period of years they show a slight reduction in the amounts of tarry matter and smoke; this can be accounted for by the replace. ment of many domestic fires by the more efficient combustion units of blocks of flats. A distinction could be drawn between the effects of domestic and industrial combustion. For example, on week-days the smoke to sulphur ratio is at a minimum during the night, when most domestic fires die down, while some industry keeps running. At week-ends, when a greater proportion of industry is closed down, and domestic fires are burning for longer periods, this ratio is found to be higher than for comparable periods during the week.

A new series of investigations has been made into the effects of discharging trade effluents into sewers. 940 samples were taken, and of these 193 , or 20.4 per cent, were considered to contravene the appropriate Act. Of this number, 86 were discharges with varying degrees of acidity. The acids identified included hydrochloric from pickling shops, nitric acid from photo-engravers, sulphuric acid from plating and anodizing shops, acetic acid from pickle manufacturers, citric acid from soft drink manufacturers and formic acid used for descaling and cleaning cookers. Also found were mixed organic acids similar to acetic acid from distilleries, bakeries and other works using fermentation processes. Wastes containing suspended matter in sufficient quantity to cause deposition and partial blockage of the sewers were those containing fats, thick mineral oils, tar, paint residues, vegetable fibres and tannery wastes.

In two cases, complete blockage of pipe sewers had taken place. One of these was caused by the wet grinding of stone and the other by a mixture of siliceous material and caustic metasilicate from a vitreous enamelling works. Of wastes containing inflammable solvents, the larger number were from garages, consisting of mixtures of waste lubricating oil with varying quantities of paraffin and petroleum spirit. One sample contained 37 per cent by volume of petroleum spirit. Three wastes from paint works contained white spirit or solvent naphtha. Another waste consisting of wash and cooling water, from a biological products plant, contained traces of monochlorbenzene and was sufficiently hot and of such total volume that the solvent, vaporized in the sewer, rendered the atmosphere unbreathable. Waste heat contained in process and cooling waters was another source of nuisance and possible dangers in the sewers. About forty cases of diseharges above the $110^{\circ} \mathrm{F}$. temperature limit laid down in the Act were investigated during the year. The adviser recommends that manufacturers should consider ways and means of recovering such waste heat in the interests of efficiency and economy.

In many cases following the examination of samples which contravene the Act, officers of the Scientific Branch and of the Chief Engineer's Department visit. the premises to bring to the notice of the occupiers the particular nature of the offence and to discuss the problems involved in treating the discharges. 